Is a HIP Always a HIP? The Case of Learning Communities

\author{
Kevin Fosnacht \\ Indiana University
}

Polly A. Graham

Indiana University

Corresponding author:

Kevin Fosnacht, Ph.D.

Indiana University Center for Postsecondary Research

201 N. Rose Ave.

Bloomington, IN 47405

kfosnach@indiana.edu

812-856-1961

ORCid: 0000-0003-3730-9442

Twitter: @k_fosnacht

The Version of Record of this manuscript has been published and is available in the Journal of Student Affairs Research and Practice May 2021

https://www.tandfonline.com/doi/10.1080/19496591.2021.1885423. 
Is a HIP Always a HIP? The Case of Learning Communities

\begin{abstract}
With the increasing adoption of learning communities, it is imperative to document their effectiveness. Using a large, longitudinal, multi-institutional dataset, we found that linkedlearning communities have a positive impact on students' engagement and perceived gains. We also found that the estimated effect of learning communities varies widely across institutions on a variety of measures. Some learning communities are very beneficial, while others have a negligible impact on students.
\end{abstract}

Keywords: Learning Communities, High-Impact Practices, Student Engagement, College Students, Program Implementation 


\section{Is a HIP Always a HIP? The Case of Learning Communities}

Concerns about collegiate quality are nearly as old as U.S. higher education itself (Thelin, 2011). In the 1980s, concerns about college quality surfaced at the national level (Association of American Colleges, 1985; National Institute of Education, 1984; U.S. Department of Education, 1983), prompting a revival of interest in learning communities. Learning communities are varyingly defined, but typically involve a restructuring of the curriculum to deepen student learning through sustained connection to peers, professors, and academic material. At their most basic level, Kuh (2008) defines learning communities as a group of "students [that] take two or more linked courses as a group and work closely with one another and with their professors" (p. 10). Many institutional leaders and scholars believe learning communities_emphasizing social connections, academic cohesion, and high levels of engagement - are important vehicles for addressing concerns about quality (e.g., Kuh, 2008; Pike, Kuh, \& McCormick, 2011; Shapiro \& Levine, 1999). Over the past 25 years, hundreds of institutions across the country have utilized learning communities in their educational programming (Laufgraben \& Shapiro, 2004; Soria \& Mitchell, 2015). Learning communities' ongoing appeal is not surprising given their association with a host of positive outcomes, including persistence and retention (Gebauer, Watterson, Malm, Filling-Brown, \& Cordes, 2013; Hill \& Woodward, 2013; Johnson, 2000), increased faculty-student interaction (Pike, 1999; Pike et al., 2011; Zhao \& Kuh, 2004), and higher grades (Stassen, 2003). As higher education rhetoric continues to shift focus beyond access to success and completion (Alderman, 2007; Engstrom \& Tinto, 2008), learning communities are promising interventions.

Learning communities are one form of a suite of practices referred to as high-impact practices (HIPs), which research has shown to enhance student learning and success (AAC\&U, 
2007; Finley \& McNair, 2013; Kuh, 2008). HIPs' effectiveness is attributed to students' high level of effort, a considerable investment of time, and commitment to the collegiate experience (Kuh, 2008). Learning communities were identified as a HIP due to their positive association with a host of outcomes (Kuh, 2008). HIPs are often used as a proxy for academic quality (Hatch, 2012), signifying the likelihood of positive outcomes. HIPs' benefits can vary, cautioning against a blind adoption (Kilgo, Ezell Sheets, \& Pascarella, 2015; Johnson \& Stage, 2018; Kuh, 2008).

In this manuscript, we seek to quantify how the effectiveness of learning communities varies across a host of outcomes. While the mere presence of HIPs is often used as a sign of educational quality (Hatch, 2012), additional research is needed to nuance their effectiveness. We hope our findings contribute to the ongoing conversations about HIP quality and inspire practitioners to improve their programming continuously.

\section{Previous Literature}

Defining learning communities has been difficult for researchers as they have varied forms and designs. Love (2012) stated that learning communities are "associated with an intentional restructuring of the curriculum and student course-taking patterns to emphasize an interdisciplinary focus with attention paid to students' academic and social development” (p. 7). Generally speaking, learning communities are intentionally formed groups of students and faculty to maximize learning (Lenning \& Ebbers, 1999). Lenning and Ebbers (1999) classified learning communities into four typologies along the following dimensions: (1) curricular, (2) classroom, (3) residential, and (4) student-type. Lenning and Ebber's (1999) classifications draw attention to the scope of learning communities, as they include small-scale groups of students learning together in a classroom to the more intense community of students living and learning 
together in a residence hall.

The Washington Center, a national resource center for learning communities, attempts to delimit the wide-range of practices designated as "learning communities." It has identified three minimum standards for learning communities: (1) "a strategically-defined cohort of students taking courses together which have been identified through a review of institutional data, (2) robust, collaborative partnerships between academic affairs and student affairs, and, (3) explicitly designed opportunities to practice integrative and interdisciplinary learning" (Washington Center, n.d., para. 4). Despite the existence of learning community standards, this definition is more of an ideal than a standard (Cross, 1998; Kuh, 2008). Due to this variability, many learning communities, in practice, appear not to follow the best practices that have been established by the field.

Despite the broad scope of learning communities, research from the past 25 years has largely confirmed their benefits. For example, using data from the National Survey of Student Engagement (NSSE), two studies found that participation in learning communities, defined as "a formal program where groups of students take two or more classes together, and may or may not have a residential component" (Zhao \& Kuh, 2004, p. 119), was positively related to academic performance, student engagement in educationally purposeful activities, college attendance, and satisfaction (Pike et al., 2011; Zhao \& Kuh, 2004). Learning community programs were positively associated with STEM students' quality of peer and faculty interactions (Soldner et al., 2012). Learning community participation has been associated with an increase in student satisfaction (Ericksen \& Walker, 2015; Johnson \& Romanoff, 1999; Lenning \& Ebbers, 1999; Zhao \& Kuh, 2004). Others have demonstrated learning community participation's relationship to retention and persistence (Johnson, 2000; Gebauer et al., 2013; Hill \& Woodward, 2013), 
especially for participants from traditionally underserved populations (Nosaka \& Novak, 2014; Ericksen \& Walker, 2015; Huerta \& Bray, 2013).

Although a great deal of literature highlights the benefits of learning communities, some literature questions the assumption that participation has uniformly positive impacts. Heaney and Fisher (2011) demonstrated that learning communities engender high social integration, but the relationship varies across student-types. Their results indicated that students who struggled with social adaptation and homesickness did not experience the positive effects as their peers. Jaffee (2007) pointed out that "positive outcomes are a contingent rather than the automatic result of FLC [freshman learning community] programs" (p. 66). Jaffee also found that learning communities can unintentionally foster conditions that delay academic development, precipitating regressive behavior conformity, inciting role conflict, and encouraging groupthink, among other adverse outcomes.

Due to the mixed findings regarding learning communities, it is essential to understand better their efficacy (Finley \& McNair, 2013). For example, a well-run learning community program might be highly effective. In contrast, a hastily created program created to appease accreditors may have limited effectiveness or be detrimental to students' learning and development. We suspect that the implementation of HIPs is not uniformly optimal, as they frequently fail to convey basic best practices such as identifying learning outcomes (Finley \& McNair, 2013; Washington Center, n.d.). In this study, we take a step to improve the field's understanding of the impacts of learning communities by examining the estimated variability in their effectiveness on various dimensions of engagement across 83 institutions. Our findings help identify if learning communities are a simple solution to solve many issues in higher education or if learning communities need to be continuously assessed to improve student outcomes. 


\section{Theory}

Student engagement and social capital theory guided the study. Both theories offer cogent explanations as to why learning communities are positioned to bring about positive outcomes. While the theories are associated with different disciplines, they can be understood as complementary. Student engagement theory argues that the quality and quantity of students' effort, as well as institutional efforts, matter to student success. In contrast, social capital theory asserts that social networks and the corresponding trust developed among individuals within the social network demarcates opportunities (Halpern, 2005). Learning communities are constructed in ways that are likely to foster valuable social connections.

The concept of student engagement can be traced back nearly a century to the work of Tyler (1932). It owes its current form to the work of various higher education theorists, including Pace (1980), Astin (1984), Chickering and Gamson (1987), and Kuh et al. (1991). Although investigating a similar construct, each of these theorists had a slightly different emphasis and terminology. Pace (1980) emphasized effort; Astin's (1984) focus was involvement; Chickering and Gamson (1987) stressed interactions, and Kuh et al. (1991) foregrounded institutional environment and the co-curricular.

Astin (1984) defines involvement as the "amount of physical and psychological energy that the student devotes to the academic experience" (p. 518). As Wolf-Wendel, Ward, and Kinzie (2009) point out, the unit of analysis in Astin's work is the individual. It is the individual who determines her level of involvement. Student engagement theory emphasizes both students' time and effort as well as institutional efforts to support students' learning and development. Engagement goes beyond involvement as it takes into account not only student efforts but also institutional policies and practices, like learning communities, which contribute to student 
success (Kuh, 2005). Institutional efforts include creating a climate that enables programs that encourage, and a curriculum that promotes student learning and development for all students and must be cross-cultural (Quaye \& Harper, 2015). Learning communities are programs designed by institutions to foster student engagement in- and outside of the classroom and have the ability to be targeted and tailored to small groups of students. Learning communities enhance the likelihood for students to succeed through the intentional time and effort expended by both students and institutions.

While a variety of definitions of social capital exist, Halpern (2005) argues the theory has three central tenets: (1) a network; (2) a network with shared norms, values, and expectations; and (3) the network enforces sanctions, positive or negative consequences for behavior in the maintenance of the status quo. The potential power of social capital comes from access to power and resources (e.g., financial, human, material) that due to the social group(s) to which an individual belongs. Learning communities, "intentionally reorganize courses or restructure the curriculum completely so that students, together with their peers and teachers, can build more meaningful connections to each other and what they are learning" (Shapiro \& Levine, 1999, p. 16). In other words, learning communities are designed to build relationships between a student, their peers, and faculty. The networks formed through learning communities can increase information flows, which would allow a student to more easily become aware of campus events, special educational opportunities, and access campus resources that promote student learning and development. Additionally, social capital contends that connections such as the ones fostered in learning communities engender reciprocity and trust among individuals, which helps facilitate students' perceptions that they are a valued member of the campus community. Learning communities, as evident from its name, are structured to build mini-communities within larger 
institutions and thereby facilitate their entry into the broader institutional culture.

\section{Research Questions}

While much research has correlated learning community participation with positive student outcomes, the existing research focuses on a single institution or averages the effects across institutions. Little is known about the variability across institutions in regards to how learning communities influence student outcomes. We examined the influence of learning communities using a multi-institutional sample, focusing on the variability in programmatic effects across institutions. The research questions guiding this inquiry were the following:

1. What is the relationship between learning community participation and student engagement and self-perceived gains for bachelors seeking first-year students, controlling for other factors?

2. To what extent does the relationship between learning communities and student engagement and self-perceived gains vary between institutions, controlling for other factors?

\section{Methods}

\section{Data}

To answer these research questions, we utilized a sample of full-time, first-year students who responded to the 2013 administration of the Beginning College Survey of Student Engagement (BCSSE) and 2014 administration of the National Survey of Student Engagement (NSSE). BCSSE is a survey administered during orientation or before enrollment that examines first-year students' high school experiences and college expectations. In contrast, NSSE is administered in the winter during the academic year and focuses on students' college experiences and administered to first-year and senior students. We excluded from our sample students who 
attended a special-focus institution (e.g., seminaries, conservatories, and engineering schools) due to the specialized nature of these institutions. Due to our focus on learning communities, we eliminated students from our sample who attended institutions where less than $5 \%$ of the firstyear respondents indicated they participated in a learning community to ensure that a critical mass of students participated in a learning community. Additionally, we removed international students $(n=621)$ from our dataset as many learning communities are designed for and targeted at domestic students. Also, our analyses utilized many variables focusing on the high school experiences of the respondents, which may not apply to international students.

After accounting for these exclusions, our sample included 9,986 students who attended 83 institutions. Seventeen percent of the sample participated in a learning community. Seven out of 10 students sampled were females. Seventy-five percent of the students identified as White, while Asians, African Americans, and Hispanics or Latinos, each comprised 5\% of the sample. The remaining students were multi-racial or classified as "Other." About a third of the students were first-generation. A quarter of the sample attended doctoral universities, $44 \%$ were enrolled in master's colleges and universities, while the remaining students attended baccalaureate colleges.

Our primary dependent variables were the 10 NSSE Engagement Indicators and a perceived gains index. The Engagement Indicators were introduced in conjunction with the updated NSSE in 2013 and are summary measures of student engagement. The ten Engagement Indicators are:

- Higher-Order Learning

- Reflective \& Integrative Learning

- Quantitative Reasoning 
- Learning Strategies

- Collaborative Learning

- Discussions with Diverse Others

- Student-Faculty Interaction

- Effective Teaching Practices

- Quality of Interactions

- Supportive Environment

The Engagement Indicators were chosen as our dependent variables to represent students' participation in effective educational practices, which prior research has shown to be linked to students' learning and development (McCormick, Kinzie, \& Gonyea, 2013). The Cronbach's $\alpha$ of the Engagement Indicators range from .77 to .87 , with all but one greater than .80 . NSSE's (2014b) Psychometric Portfolio contains additional information on their validity. In addition to the Engagement Indicators, we also used a perceived gains index as a dependent variable. The index is a composite of 12 items inquiring about how students' college experience improved their knowledge, skills, and personal development. The Cronbach's $\alpha$ for Perceived Gains was .90. All of the dependent variables were standardized with a mean of 0 and a standard deviation (SD) of 1 to allow for the efficient estimation of effect sizes by learning community participation.

Our key independent variable was learning community participation. Students who indicated they participated or were currently involved in a "learning community or some other formal program where groups of students take two or more classes together" were coded as having participated in a learning community. We coded all other students as not having participated in a learning community. 
The control variables utilized included a variety of data on students' characteristics, high school experiences, and expectations for college. Our data on students' sex, race, and standardized test score (SAT or ACT equivalent) were reported by their institutions, while all other data was self-reported by students on BCSSE and NSSE. We used a number of student characteristics to control for self-selection into a learning community. These characteristics included high school grades, parental education, distance from home to college, and the number of friends attending the same college. These variables were selected as proxies for students' knowledge of special opportunities, like learning communities, via their social networks, which could influence their decision to participate in a learning community. Additionally, we also included students' anticipated major, as learning communities are frequently themed, and interest in a field of study could be an eligibility requirement or a factor leading students to participate. We captured high school experiences through the following BCSSE scales on high school engagement and selected items related to the quality of high school engagement in effective educational practices: quantitative reasoning, learning strategies, time spent preparing for class, participating in co-curricular activities, and relaxing and socializing, and the extent to which their courses challenged them. Other BCSSE scales were selected as they act as pre-tests for our within college dependent variables: collaborative learning, student-faculty interaction, discussions with diverse others, and importance of the campus environment (the previously mentioned BCSSE scales, quantitative reasoning, and learning strategies, also served as pre-test measures. Variables on students' involvement in performing or visual arts programs, athletic teams, student government, publications, vocational clubs, and volunteering were utilized. These variables were selected to account for students' inclination to participate in social activities and because they may be a prerequisite for participation in a themed learning community. Finally, 
data on the following BCSSE scales were used to account for students' expectations for college: expected academic perseverance, expected academic difficulty, and perceived academic preparation. For results on the validity and reliability of the BCSSE scales, see Cole and Dong (n.d.). The codebook for the dataset is available from NSSE (2014a).

Our theoretical framework guided our selection of the control variables, which was particularly important due to the lack of previous research indicating the correlates of learning community participation. In addition to focusing on common demographic characteristics, we selected variables such as the number of friends also attending the same college to indicate the power of social networks in distributing information on the possibility and value of participating in a learning community. Similarly, we included variables on high school experiences and major choice to represent students' interest in activities or topics that may form the basis of learning communities like community service or the sciences.

We utilized multiple imputation by chained equations (MICE) to impute missing data (Raghunathan, Lepkowski, Van Hoewyk, \& Solenberger, 2001; Rubin, 1987). Our primary rationale to impute data was to have consistent sample sizes across the analyses described below. MICE uses a series of regression models to impute missing data and allows for each variable to be modeled according to its distribution. We created a total of 20 imputed datasets to minimize the loss of statistical power while keeping the time to run the imputation and analytic models reasonable (Graham, Olchowski, \& Gilreath, 2007). Continuous variables were imputed using predictive mean matching. Binary, ordinal, and nominal variables were imputed using the appropriate form of logistic regression.

\section{Analyses}

We performed the following procedures for each of our 11 dependent variables. Our 
analyses utilized multilevel modeling due to the nested nature of our data and its ability to describe how the relationship between a dependent and independent variable varies across institutions. We began our analyses by estimating a null model to calculate the intra-class correlation (ICC), which is the proportion of variance attributable to between-institution factors. We also used the ICCs to calculate the design effects, which compare the variability between a clustered dataset and a simple random sample of the same size. Design effects greater than 2 indicate a need for multilevel modeling (Peugh, 2010). Next, we estimated a multilevel model that included an indicator for learning community participation, the control variables noted in the data section, an institution-specific random intercept, and the institution-specific random coefficient (also known as a random slope) for the learning community variable. Due to our focus on the influence of learning community participation on student engagement and its variability across institutions, the key parameters of interest in the model were the fixed effect estimate of learning community participation and its random effect, which describes its variability. For each dependent variable, we used the fixed effect estimate and the random effect to calculate the estimate for a program at -2 standard deviations (SDs), -1 SDs, +1 SDs, and +2 SDs from the fixed-effect estimate to highlight the variability in how learning communities differ across institutions. This range of estimates provides the $95 \%$ confidence interval at the school level.

As our data utilized multiple imputation, all results are the average of the estimates from the 20 imputed datasets. Standard errors were adjusted to account for the uncertainty of the imputation, according to Rubin's (1987) rules for multiple imputation, and the nesting of students within schools. We used StataIC to conduct all analyses (Statacorp, 2016).

\section{Positionalities}


Our research was conducted at the Center for Postsecondary Research (CPR), which “investigates processes and practices that influence student success and institutional excellence in higher education and promotes those found to be effective" (Center for Postsecondary Research, n.d.). We believe in the mission of CPR and embarked on this study with the belief that evidence can be leveraged to improve the student experience in college. One author worked in admissions for two years and subsequently has focused on student success research as a graduate student and faculty member. A quTheyantitative researcher by training, his work seeks to identify programs and policies that facilitate student success. The other author spent the early part of her career in student affairs, developing a living-learning program at a small, liberal arts institution in the Midwest. She believes that interventions such as learning communities have the potential to positively impact student outcomes. She is convinced that impacts often vary by identity characteristics due to sociocultural factors, including discrimination.

\section{Limitations}

Before presenting the results, we need to acknowledge the study's limitations. Our data is not a random sample of all postsecondary students in the U.S; instead, it utilizes students who attended institutions that chose to participate in both BCSSE and NSSE. Our results may be subject to self-selection bias, particularly at the institution level. In particular, our sample contains more White students than the overall first-year population attending four-year colleges (75\% vs. 57\%; National Center for Education Statistics, n.d.). Due to a lack of data, our results neglect the variability of learning community programs within institutions. Institutions have different models for administering learning communities, and the effect of learning communities is most likely not constant across the different types of learning communities. For example, a learning community that involves both curricular and residential components may have a 
different impact on students than one only featuring a curricular component, even if located at the same institution, making our variability estimates conservative. Additionally, our results focus on changes in various facets of student engagement and students' perceived gains in learning and holistic development. A learning community may be designed to improve only some aspects of the student experience; the lack of an effect in a specific domain should not be viewed as an indictment of the entire program.

\section{Results}

The ICCs from our null models were generally low $(<0.05)$, indicating that most variance in the dependent variables is attributable to within school variance. The design effects were all greater than 2.0, indicating a need for multilevel modeling (Peugh, 2010).

Table 1 contains the fixed-effects estimates of learning community participation on student engagement and perceived gains. As the dependent variables were standardized with a mean of 0 and SD of 1 , the estimates represent the expected effect size change in the dependent variable associated with participating in a learning community, holding other factors constant. Overall, the estimates indicate that learning community participation is positively and significantly associated with an increase in student engagement across a variety of domains and students' self-perceived gains. The exception, Effective Teaching Practices, had a positive coefficient; however, the estimate narrowly missed the threshold for significance at $p<.05$.

The estimated coefficients for Higher-Order Learning, Quantitative Reasoning, Learning Strategies, Discussions with Diverse Others, Quality of Interactions, Supportive Environment, and Perceived Gains all ranged between .10 and .19 in SD units. The coefficients for Reflective \& Integrative Learning and Collaborative Learning fell between .20 and .29 in SD units. The largest estimate at .33 SDs was for Student-Faculty Interaction. The Snijders and Bosker's level 
one $\mathrm{R}^{2}$ coefficient indicated that the amount of variance accounted for at the student-level ranged between $6 \%$ and $19 \%$.

---Insert Table 1 About Here---

---Insert Figure 1 About Here---

Next, we focused on the extent to which the relationship between learning community participation and our dependent variables varied across institutions. The results demonstrating the variability in the estimated effects of learning community participation are visually displayed in Figure 1. The dark boxes represent the estimated population-mean effect sizes plus or minus one standard deviation of the estimated random coefficient for learning community participation. We would expect the estimated effects of learning communities at two out of three schools to fall within the black boxes. The grey lines extend out to plus or minus two standard deviations, and we would expect about $95 \%$ of the estimated effects to be within this range.

Virtually no variability in the estimated effects between institutions was found for the following dependent variables: Learning Strategies, Collaborative Learning, Quality of Interactions, and Perceived Gains. The relationship between learning community participation and these variables appears to be highly consistent across institutions. In contrast, the range from the $5^{\text {th }}$ percentile to the $95^{\text {th }}$ percentile estimates was at least .33 SDs for Higher-Order Learning, Reflective and Integrative Learning, Student-Faculty Interaction, and Supportive Environment.Tthe effect of learning communities appears to differ substantially across institutions for these variables. In between these extremes, the results for Quantitative Reasoning, Effective Teaching Practices, and Discussions with Diverse Others demonstrated some variability in the estimated relationships across institutions; however, the magnitude of the estimates was not as substantial. 
The variability in the estimated relationship between learning community participation and our dependent variables across institutions indicates that learning communities can have disparate influences on students' engagement and perceived gains. While the fixed effects estimates suggest that learning community participation has a positive influence across a variety of engagement domains, some programs appear to have a trivial impact on engagement. In particular, our results suggest that poor programs may have little to no influence $(<.10 \mathrm{SDs})$ on Higher-Order Learning, Discussions with Diverse Others, and Supportive Environment. In contrast, high performing learning community programs may have a substantial influence $(>.30$ SDs) on Higher-Order Learning, Reflective \& Integrative Learning, Student-Faculty Interaction, and Supportive Environment.

\section{Discussion}

As a HIP, learning communities have the potential to serve as a pathway to student success. In this paper, we examined the efficacy of learning communities on students' engagement and perceived gains and focused on the variability in the relationships between learning community participation across institutions. Our results comport with previous research on the impacts of learning community participation on student engagement and self-perceived gains. On average, we estimated that learning communities have a significant and positive effect on multiple facets of student engagement and students' self-perceived gains (see Table 1). The lone exception occurred for Effective Teaching Practices, as learning community participation was positively but not significantly associated with this dependent variable.

While we found significant differences in our student engagement measures by learning community participation, learning community participation does not appear to have an equivalent influence across the various domains of student engagement examined. Our results 
show that learning communities have the most substantial effects on Student-Faculty Interaction, Reflective and Integrative Learning, and Collaborative Learning. The results for the latter two dependent variables are less surprising as learning communities are frequently designed to pair students and integrate coursework frequently across a common theme, helping to integrate students into their institution's culture, norms, and expectations. The increase in Student-Faculty Interaction is more surprising due to the lack of a relationship between Effective Teaching Practices. Following social capital theory, learning communities appear to alter students' relationships with professors outside of the classroom and help incorporate students into their institution's social networks. We did not observe a corresponding increase in Effective Teaching Practices inside the classroom by instructors. This finding is intriguing as learning communities frequently are a part of an intentional restructuring of the curriculum, which should influence the classroom experience. There is the possibility that this result is attributable to program effect diffusion, as non-participants may also benefit from improved pedagogy inside the classroom if the curriculum is changed wholesale.

While learning communities appear to be effective across a variety of domains, they do not appear to alter the student experience drastically, on average. A study of effect sizes in the NSSE Engagement Indicators recommends classifying effects sizes smaller than .10 as trivial, .10 to .29 as small, .30 to .49 as medium, and .50 or above as large (Rocconi \& Gonyea, 2018). Except for the Effective Teaching Practices (trivial) and Student-Faculty Interaction (medium) estimates, nearly all of our effect size estimates were between .10 and .29 and should be classified as small.

While the above results reflect the population average effect of learning communities, we found substantial variation in the estimated effects across institutions in 6 of our 11 dependent 
variables. Our findings comport with other research that demonstrates learning communities vary in their effects, even learning communities at the same institution (Purdie \& Rosser, 2011). In particular, the estimates for Higher-Order Learning, Reflective \& Integrative Learning, StudentFaculty Interaction, and Supportive Environment ranged from trivial for institutions with the least impactful programs to medium or large for the most impactful institutions. The effects of learning communities on students' experiences appear to vary substantially across institutions. This finding suggests that the nature and structure of a learning community are linked with its effectiveness and that merely implementing a learning community program will not automatically improve all facets of students' learning and development. Likely, the quality of institutional time and effort varies. As we mentioned previously, the theory of engagement maintains that learning communities enhance the likelihood for students to succeed through the intentional time and effort expended by both students and institutions. Differences in outcomes may be the result of inconsistent quality of effort and time by institutional personnel or students. The estimates for Collaborative Learning, Perceived Gains, Quality of Interactions, and Learning Strategies were highly consistent across schools and non-trivial. We conclude that learning communities' primary feature of having a cohort of students attending the same courses together appears to be a practical approach to promoting these types of student engagement and perceived gains.

\section{Implications for research}

This study attempted to provide more concrete evidence for the effectiveness of learning communities. Our results comport with previous research on learning communities, validating others' findings that learning communities are an important tool for improving student learning and success. We also discovered that all learning communities are not created equal. The natural 
follow-up question is which types of learning communities are most effective and why. In addition to answering this vital question, research should also focus on how the effects of learning communities vary by different student populations (e.g., race and ethnicity, gender, socio-economic status).

\section{Implications for practice}

Our study corroborates previous research that learning communities are effective means of encouraging students to engage in activities that previous research has demonstrated to promote student learning and success (McCormick et al., 2013). Practitioners must take into account the variance among learning communities as well as the relatively small effect sizes and have realistic expectations. In other words, there are better and worse learning communities, and even the best ones will not in and of themselves solve all student success concerns. This understanding should inform resource allocation decisions and encourage decision-makers to thoughtfully develop or sustain learning communities on their campuses (Finley \& McNair, 2013). In particular, we echo Finley and McNair's (2013) recommendation that the administrators of learning communities should be more intentional in articulating the learning outcomes associated with a learning community and how learning community participation will help prepare students for their careers.

In this vane, we strongly recommend frequent assessment of individual learning communities. The assessments should focus on both the effectiveness of the community and student demand. In terms of educational effectiveness, assessors should focus on long-term metrics like persistence and grades. In the short-term, assessments of programming and generalized student engagement in effective educational activities should occur in both academic and social domains. We also encourage disaggregating data to assess how learning communities 
influence student subgroups. For example, a large-scale study has identified that the majority of the benefits of residential learning community participation on persistence go to male students (Authors, 2020). A better understanding of how a learning community impacts particular student groups will allow decision-makers to be targeted in their improvements.

In addition to assessing education and social outcomes, we recommend that learning communities frequently assess student demand, particularly for themed communities. A benefit of many learning communities' structure is that they can be adapted to suit student needs annually. Annual demand assessments should be made, and, if needed, programs should be restructured. Administrators should also continuously monitor new course offerings to seed new communities. If student demand in a topic is sufficient for a learning community, administrators should suggest the topic to the faculty of the appropriate department to consider adding a new themed course to the curriculum. We view learning communities as living organisms that should be highly reactive to student needs and be reformulated if they are suboptimal.

It is also prudent to take into account learning community scholarship recommendations as well as regularly assess individual programs. Our research suggests that learning communities may not address pedagogical issues. While learning communities can foster higher levels of integrative learning and faculty-student interaction, ineffective programming, and practices can persist within learning communities. Staff designing learning communities may benefit from including their colleagues from teaching and learning centers or other resources that seek to develop effective teaching practices.

\section{Conclusion}

With the increasing adoption of learning communities by postsecondary institutions to improve student learning and development, it is imperative to document the effectiveness of 
learning communities. In this study, we found that learning communities have a positive impact on students' engagement and perceived gains, confirming previous research; however, this effect does not drastically alter the student experience on average. Additionally, we found that the estimated effect of learning communities varies widely across institutions on a variety of measures. It appears that while some learning communities are exceptionally beneficial, others have a negligible impact on students. Institutions should not assume that only having and maintaining a program termed "learning community" is beneficial for students. Instead, careful attention must be given to incorporate best practices, assess their benefits, and make the necessary changes to genuinely "highly impact" student success. 


\section{References}

Adelman, C. (2007). Do we really have a college access problem?. Change: The Magazine of Higher Learning, 39(4), 48-51.

Association of American Colleges (1985). Integrity in the curriculum: Report to the academic community. Washington, D. C.: Association of American Colleges.

Association of American Colleges and Universities. (2007). College learning for the new global century. Washington, DC: Author.

Astin, A. W. (1984). Student involvement: A developmental theory for higher education. Journal of College Student Personnel, 25, 297-308.

Author. (2020). Details suppressed for blind review.

Brower, A. M., \& Inkelas, K. K. (2010). Living-learning programs: One high-impact educational practice we now know a lot about. Liberal Education, 96(2), 36-43.

Center for Postsecondary Research. (n.d.). Mission. Retrieved from https://cpr.indiana.edu/about.cfm

Chickering, A. W., \& Gamson, Z. F. (1987). Seven principles for good practice in undergraduate education. AAHE bulletin, 39(7), 3-7.

Cole, J. \& Dong, Y. (n.d.) Confirmatory factor analysis of the BCSSE scales. Bloomington, IN: Indiana University Center for Postsecondary Research.

Cross, K. P. (1998). Why learning communities? Why now. About Campus, 3(3), 4-11.

Engstrom, C., \& Tinto, V. (2008). Access without support is not opportunity. Change: The Magazine of Higher Learning, 40(1), 46-50.

Ericksen, K. S., \& Walker, J. M. (2015). The value of academic affairs and student affairs collaboration: Living-learning communities at historically black colleges and 
universities. Journal of Research Initiatives, 1(3), Article 2.

Finley, A. P., \& McNair, T. (2013). Assessing underserved students' engagement in high-impact practices. Washington, DC: Association of American Colleges and Universities.

Gebauer, R. D., Watterson, N. L., Malm, E., Filling-Brown, M. L., \& Cordes, J. W. (2013). Beyond improved retention: Building value-added success on a broad foundation. Learning Communities Research and Practice, 1(2), Article 4.

Graham, J. W., Olchowski, A. E., \& Gilreath, T. D. (2007). How many imputations are really needed? Some practical clarifications of multiple imputation theory. Prevention Science, 8, 206-213.

Hatch, D. K. (2012). Unpacking the black box of student engagement: The need for programmatic investigation of high impact practices. Community College Journal of Research and Practice, 36(11), 903-915.

Heaney, A., \& Fisher, R. (2011). Supporting conditionally-admitted students: A case study of assessing persistence in a learning community. Journal of the Scholarship of Teaching and Learning, 11, 62-78.

Hill, W., \& Woodward, L. S. (2013). Examining the impact learning communities have on college of education students on an urban campus. Journal of College Student Development, 54, 643-648.

Huerta, J. C., \& Bray, J. J. (2013). How do learning communities affect first-year Latino students? Learning Communities Research and Practice, 1(1), Article 5.

Inkelas, K. K., Soldner, M., Longerbeam, S., \& Leonard, J. (2008). Differences in student outcomes by types of living-learning programs: The development of an empirical typology. Research in Higher Education, 49, 495-512. 
Jaffee, D. (2007). Peer cohorts and the unintended consequences of freshman learning communities. College Teaching, 55, 65-71.

Johnson, J. L. (2000). Learning communities and special efforts in the retention of university students: What works, what doesn't, and is the return worth the investment?.Journal of College Student Retention, 2, 219-238.

Johnson, J. L., \& Romanoff, S. J. (1999). Higher education residential learning communities: What are the implications for student success?.College Student Journal, 33(3), 385-400.

Johnson, S. R., \& Stage, F. K. (2018). Academic engagement and student success: Do highimpact practices mean higher graduation rates?. The Journal of Higher Education, 89(5), 753-781.

Kilgo, C. A., Ezell Sheets, J. K., \& Pascarella, E. T. (2015). The link between high-impact practices and student learning: Some longitudinal evidence. Higher Education: The International Journal Of Higher Education And Educational Planning, 69(4), 509-525.

Kuh, G. D. (2005). Promoting student success: What campus leaders can do (Occasional Paper No. 1). Bloomington, IN: Indiana University Center for Postsecondary Research.

Kuh, G. D. (2008). High-impact educational practices: What they are, who has access to them, and why they matter. Washington, DC: Association of American Colleges \& Universities.

Kuh, G. D., O’Donnell, K., \& Reed, S. (2013). Ensuring quality and taking high-impact practices to scale. Washington, DC: Association of American Colleges \& Universities.

Laufgraben, J. L., \& Shapiro, N. S. (2004). Sustaining and improving learning communities. San Francisco, CA: Jossey-Bass.

Lenning, O. T., \& Ebbers, L. H. (1999). The powerful potential of learning communities: Improving education for the future. ASHE-ERIC Higher Education Reports, 26 (6). 
Washington, DC: The George Washington University, Graduate School of Education and Human Development.

Love, A. G. (2012). The growth and current state of learning communities in higher education. In K. Buch \& K. E. Barron (Eds), Discipline-Centered Learning Communities: Creating Connections Among Students, Faculty, and Curricula (pp. 5-15). New Directions for Teaching and Learning, 132. San Francisco, CA: Jossey Bass.

McCormick, A. C., Kinzie, J. \& Gonyea, R. M. (2013). Student engagement: Bridging research and practice to improve the quality of undergraduate education. In M. B. Paulsen (Ed.). Higher Education: Handbook of Theory and Research, (Vol. 28, pp. 47-92). Dordrecht, The Netherlands: Springer.

National Center for Education Statistics. (n.d.). Integrated Postsecondary Education Data System [Data set]. Retrieved from https://nces.ed.gov/ipeds/use-the-data National Study of Living-Learning Programs. (2007). National Study of Living-Learning Programs: 2007 report of findings. College Park: National Study of Living-Learning Programs.

National Institute of Education. (1984). Involvement in learning: Realizing the potential of American higher education. Washington, D.C.: U.S. Department of Education.

National Survey of Student Engagement. (2014a). BCSSE 2013-NSSE 2014 Combined Codebook (U.S. Version). Retrieved from http://nsse.indiana.edu/2014_Institutional_Report/data_codebooks/BCSSE\%202013NSSE\%202014\%20Combined\%20Codebook.pdf.

National Survey of Student Engagement. (2014b). NSSE 2014 Engagement Indicators-Internal Consistency Statistics. Retrieved from 
http://nsse.indiana.edu/2014_institutional_report/pdf/EI Intercorrelations 2014.pdf.

Nosaka, T., \& Novak, H. (2014). Against the odds: The impact of the key communities at Colorado State University on retention and graduation for historically underrepresented students. Learning Communities Research and Practice, 2(2). Article 3.

Peugh, J. L. (2010). A practical guide to multilevel modeling. Journal of School Psychology, 48, $85-112$.

Pike, G. R. (1999). The effects of residential learning communities and traditional residential living arrangements on educational gains during the first year of college. Journal of College Student Development, 40, 269-284.

Pike, G. R., Hansen, M. J., \& Lin, C. H. (2011). Using instrumental variables to account for selection effects in research on first-year programs. Research in Higher Education, 52, 194-214.

Pike, G. R., Kuh, G. D., \& McCormick, A. C. (2011). An investigation of the contingent relationships between learning community participation and student engagement. Research in Higher Education, 52, 300-322.

Purdie, J. R., \& Rosser, V. J. (2011). Examining the academic performance and retention of firstyear students in living-learning communities and first-year experience courses. College Student Affairs Journal, 29(2), 95-112.

Quaye, S. J., \& Harper, S. R. (Eds.). (2015). Student engagement in higher education: Theoretical perspectives and practical approaches for diverse populations $\left(2^{\text {nd }} \mathrm{ed}.\right)$. New York: Routledge.

Raghunathan, T. E., Lepkowski, J. M., Van Hoewyk, J., \& Solenberger, P. (2001). A multivariate technique for multiply imputing missing values using a sequence of 
regression models. Survey methodology, 27, 85-96.

Rocconi, L. M., \& Gonyea, R. M. (2018). Contextualizing Effect Sizes in the National Survey of Student Engagement: An Empirical Analysis. Research \& Practice in Assessment, 13, 22-38.

Rubin, D. B. (1987). Multiple imputation for nonresponse in surveys. New York: Wiley.

Shapiro, N. S., \& Levine, J. H. (1999). Creating learning communities: A practical guide to winning support, organizing for change, and implementing programs. San Francisco, CA: Jossey-Bass.

Snijders, T. A. B. \& Bosker, R. J. (1994): Modeled Variance in Two-Level Models. Sociological Methods \& Research, 22, 342-363.

Snijders, T. A. B. \& Bosker, R. J. (1999): Multilevel Analysis. An Introduction to Basic and Advanced Multilevel Modeling. London: Sage.

Soldner, M., Rowan-Kenyon, H., Inkelas, K. K., Garvey, J., \& Robbins, C. (2012). Supporting students' intentions to persist in STEM disciplines: The role of living-learning programs among other social-cognitive factors. The Journal of Higher Education, 83, 311-336.

Soria, K. M., \& Mitchell, T. D. (2015). Learning communities: Foundations for first-year students' development of pluralistic outcomes. Learning Communities Research and Practice, 3(2), 2.

Stassen, M. L. (2003). Student outcomes: The impact of varying living-learning community models. Research in Higher Education, 44, 581-613.

StataCorp. (2016). Stata IC (Version 14.2) [Computer software]. College Station, TX: StataCorp. U.S. Department of Education. (1983). A nation at risk: The imperative for educational reform. Washington, D.C.: Author. 
Wolf-Wendel, L., Ward, K., \& Kinzie, J. (2009). A tangled web of terms: The overlap and unique contribution of involvement, engagement, and integration to understanding college student success. Journal of College Student Development, 50, 407-428.

Zhao, C. M., \& Kuh, G. D. (2004). Adding value: Learning communities and student engagement. Research in Higher Education, 45(2), 115-138. 
Table 1

Fixed effects estimates of learning community participation

\begin{tabular}{lrlllrrr} 
Dependent Variable & Est. & Sig. & \multicolumn{2}{l}{$95 \% \mathrm{CI}$} & $\mathrm{R}^{2}{ }_{\mathrm{L} 1}{ }^{1}$ & $\mathrm{R}^{2}{ }_{\mathrm{L} 2}{ }^{2}$ \\
\hline Higher-Order Learning & .17 & $* * *$ & .11 & .23 & 0.13 & 0.24 \\
Reflective \& Integrative Learning & .27 & $* * *$ & .21 & .33 & 0.19 & 0.34 \\
Quantitative Reasoning & .15 & $* * *$ & .09 & .20 & 0.15 & 0.27 \\
Learning Strategies & .11 & $* * *$ & .06 & .16 & 0.19 & 0.23 \\
Collaborative Learning & .23 & $* * *$ & .18 & .29 & 0.15 & 0.32 \\
Discussions w/ Diverse Others & .15 & $* * *$ & .08 & .21 & 0.16 & 0.18 \\
Student-Faculty Interaction & .33 & $* * *$ & .26 & .40 & 0.06 & 0.15 \\
Effective Teaching Practices & .06 & & .00 & .12 & 0.08 & 0.23 \\
Quality of Interactions & .13 & $* * *$ & .07 & .19 & 0.08 & -0.02 \\
Supportive Environment & .17 & $* * *$ & .10 & .24 & 0.13 & 0.09 \\
Perceived Gains & .19 & $* * *$ & .12 & .22 & 0.13 & 0.24 \\
\hline
\end{tabular}

$* p<.05, * * p<.01, * * * p<.001$

${ }^{1}$ Snijders and Bosker's (1994; 1999) level-one $\mathrm{R}^{2}$ for multilevel models

${ }^{2}$ Snijders and Bosker's $(1994 ; 1999)$ level-two $\mathrm{R}^{2}$ for multilevel models

Note: Estimates expressed in effect size units. Results are the average of 20 imputed datasets.

Standard errors were adjusted to account for the uncertainty of the imputation. The models hold constant other characteristics. 
Figure 1

Variability in the relationship between learning community participation and student engagement and perceived gains across institutions

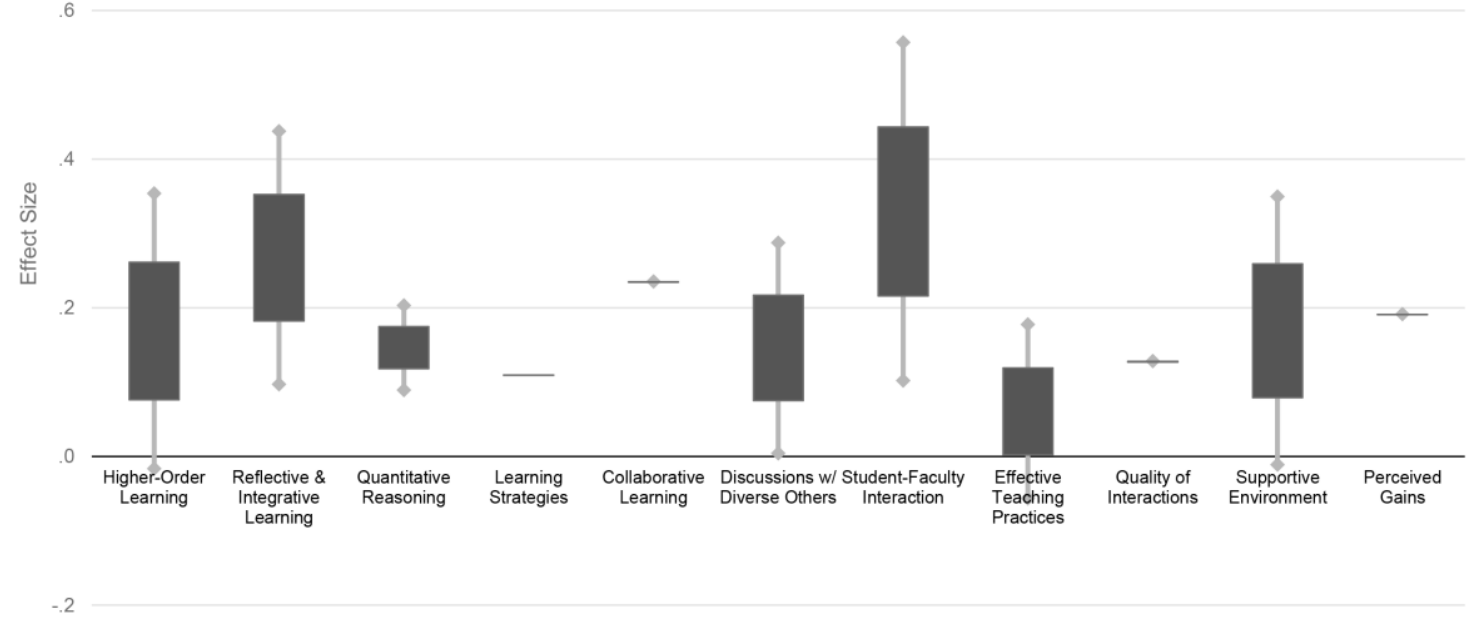

Note: The black boxes represent the population average effect size $\pm 1 \mathrm{SD}$ of the random coefficient. The grey bars represent the population average effect size \pm 2 SDs of the random coefficient. Estimates are the average from 20 imputed datasets and hold constant other characteristics. 